\title{
ESCOLA TÉCNICA DE MANAUS (ETM) À ESCOLA TÉCNICA FEDERAL DO AMAZONAS (ETFAM) - (1942-1965): uma perspectiva histórica
}

\author{
Vannessa Ribeiro da Silva ${ }^{1}$ \\ Pérsida da Silva Ribeiro Miki²
}

\section{RESUMO}

O atual estudo objetiva historicizar o processo da criação da Escola Técnica de Manaus (ETM) em 1942 e como sucedeu a modificação no ensino profissional até 1965 com a nova denominação - Escola Técnica Federal do Amazonas (ETFAM). Este artigo faz parte da dissertação intitulada "A mulher no ensino profissional em Manaus: visibilidade, espaços e dinâmicas na ETM e ETFAM (1937 a 1971)". Ao apresentar o período de 1942 a 1965, questiona-se que mudanças ocorreram no ensino profissional por meio das políticas educacionais na Escola Técnica através da Lei Orgânica do Ensino Industrial, criação do SENAI, e a LDB n 4.024/61. Analisa-se fontes documentais oficiais encontradas no Arquivo Digital Gustavo Capanema e do Arquivo Geral da Escola Técnica. No governo de Getúlio Vargas, em 1942, foi implementada a Reforma Capanema pelo Ministro da Educação Gustavo Capanema com as Leis Orgânicas do Ensino, e que regulamentaram o Ensino Secundário, Industrial, Comercial e a criação do SENAI. Com a LDB n 4.024/61 ocorreu uma reformulação na estrutura do ensino profissional e modificou novamente o ensino no país. As configurações das políticas públicas por meio dos instrumentos normativos são relevantes para se compreender a organização do ensino e da sociedade brasileira, em determinado momento, com vistas à divisão e aos processos de exclusão social.

Palavras-chave: História da Educação. Escola Técnica. Políticas Educacionais.

\footnotetext{
1 Mestre em Educação pelo Programa de Pós-Graduação em Educação da Faculdade de Educação, da Universidade Federal do Amazonas - UFAM. Orcid iD: https://orcid.org/00000003-4982-0950. E-mail: vannessa.rsilva@gmail.com

2 Professora Doutora em Educação pela Universidade São Francisco, Docente do Programa de Pós-Graduação em Educação e da Faculdade de Educação, da Universidade Federal do Amazonas - UFAM. Orcid iD: https://orcid.org/0000-0003-3684-681X. E-mail: persidamiki@gmail.com
} 


\title{
TECHNICAL SCHOOL OF MANAUS (ETM) TO THE FEDERAL TECHNICAL SCHOOL OF AMAZONS (ETFAM) - (1942-1965): a historical perspective
}

\begin{abstract}
The current study aims to historicize the process of creating the Technical School of Manaus (ETM) in 1942 and how it succeeded the change in professional education until 1965 with the new name - Federal Technical School of Amazonas (ETFAM). This article is part of the dissertation entitled "The woman in vocational education in Manaus: visibility, spaces and dynamics in the ETM and ETFAM (1937 to 1971)". When presenting the period from 1942 to 1965, it is questioned what changes occurred in professional education through the educational policies in the Technical School through the Organic Law of Industrial Education, creation of SENAI, and the LDB No. 4.024/61. Official documentary sources found in the Gustavo Capanema Digital Archive and the General Archive of the Technical School are analyzed. In the government of Getúlio Vargas, in 1942, the Capanema Reform was implemented by the Minister of Education Gustavo Capanema with the Organic Laws of Education, which regulated Secondary, Industrial, Commercial Education and the creation of SENAI. With the LDB $n^{\circ} 4.024 / 61$ there was a reformulation in the structure of the professional education and modified again the education in the country. The configurations of public policies by means of normative instruments are relevant to understand the organization of education and Brazilian society at a given moment with a view to the division and processes of social exclusion.
\end{abstract}

Keywords: History of Education. Technical School. Educational Policies.

\section{ESCUELA TÉCNICA DE MANAUS (ETM) A LA ESCUELA TÉCNICA FEDERAL DE}

\author{
AMAZONAS (ETFAM) - (1942-1965): una perspectiva histórica
}

\section{RESUMEN}

El presente estudio tiene como objetivo historizar el proceso de creación de la Escuela Técnica de Manaus (ETM) en 1942 y cómo sucedió el cambio en la educación profesional hasta 1965 con el nuevo nombre - Escuela Técnica Federal de Amazonas (ETFAM). Este artículo forma parte de la tesis titulada "La mujer en la formación profesional en Manaus: visibilidad, espacios y dinámicas en la ETM y la ETFAM (1937-1971)". Al presentar el período de 1942 a 1965, se cuestiona qué cambios se produjeron en la educación profesional a través de las políticas educativas de la Escuela Técnica a través de la Ley Orgánica de Educación Industrial, la creación del SENAI y la LDB No. 4.024/61. Se analizan las fuentes documentales oficiales encontradas en el Archivo Digital Gustavo Capanema y en el Archivo General de la Escuela Técnica. En el gobierno de Getúlio Vargas, en 1942, la Reforma de Capanema fue implementada por el Ministro de Educación Gustavo Capanema con las Leyes Orgánicas de Educación, que regulaban la Educación Secundaria, Industrial, Comercial y la creación del SENAI. Con la LDB n 4.024/61 se produjo una reformulación en la estructura de la educación profesional y se modificó nuevamente la educación en el país. Las configuraciones de las políticas 
públicas por medio de instrumentos normativos son relevantes para entender la organización de la educación y la sociedad brasileña, en un momento dado, con miras a la división y los procesos de exclusión social.

Palabras clave: Historia de la Educación. Escuela Técnica. Políticas Educativas.

\section{INTRODUÇÃO}

O presente artigo objetiva historicizar o processo da criação da Escola Técnica de Manaus (ETM), e posteriormente como ocorreu a modificação no ensino profissional com a nova denominação - Escola Técnica Federal do Amazonas (ETFAM). Para explicar esse processo questiona-se que mudanças ocorreram no ensino profissional por meio das políticas educacionais através das Leis Orgânicas do Ensino Industrial (Decreto-lei $n^{\circ} 4.073$, de 30 de janeiro de 1942), com a criação do SENAI (Decreto-lei n 4.048, de 22 de janeiro de 1942) e com as Diretrizes e Bases da Educação Nacional (Lei n 4.024, de 20 de dezembro de 1961).

Este estudo faz parte do aprofundamento da pesquisa de mestrado intitulada "Espaços da mulher no ensino profissional em Manaus (1962-1971)" e tem como finalidade analisar os espaços ocupados pela da mulher e as dinâmicas frente as suas atividades exercidas no ensino profissional na Escola Técnica de Manaus e Escola Técnica Federal do Amazonas no período de 1962 a 1971.

No período de 1940 a 1965 o Brasil foi marcado por acontecimentos históricos que trouxeram mudanças decisivas no âmbito político, econômico, educacional, e transformou toda a estrutura do ensino profissional e consequentemente influenciou a trajetória da Escola Técnica de Manaus. Ao retratar sobre a história das instituições educativas, Justino Magalhães (2004) afirma:

Na sua ação concreta e do quotidiano, como na dimensão temporal, as instituições educativas, sendo instâncias complexas e multifacetadas, engendram e desenvolvem culturas, representações, formas de organização, relacionamento e ação que se constituem em fatores de diferenciação e de identidade. Inseridas em contextos geográficos e em tempos históricos marcados por fatores de natureza sociocultural, conjunturas e circunstâncias histórica específicas, estas instituições, se bem que estruturadas por uma matriz de base e perseguindo objetivos comuns, existem de forma 
própria e este quadro existencial fomenta representações e apropriações, elas mesmas diferenciadas (MAGALHÃES, 2004, p.69).

O percurso metodológico está relacionado com as fontes encontradas no Arquivo Digital Gustavo Capanema33, nos documentos oficiais (Decretosleis e Leis), no Arquivo do IFAM4, e na literatura e pesquisas sobre o tema.

O artigo está estruturado em três itens, o primeiro historiciza a criação da ETM, o segundo sobre a criação e ensino na ETFAM, e o terceiro sobre as modificações no ensino profissional em Manaus de acordo com as políticas educacionais.

\section{CRIAÇÃO DA ESCOLA TÉCNICA DE MANAUS (ETM)}

A Escola Técnica de Manaus (ETM) foi instituída na metade do século XX, em decorrência do Decreto-Lei no 4.127 de 25 de fevereiro de 1942 que "estabelece as bases de organização da rede federal de estabelecimentos de ensino industrial". (BRASIL, 1942). Esse Decreto-lei foi resultante da Lei Orgânica do Ensino Industrial5 (Decreto-Lei n ${ }^{\circ}$ 4.073, de 30 de janeiro de 1942) e do Decreto $^{6} n^{\circ} 8.673$, de 3 de fevereiro do mesmo ano.

De acordo com o documento "Relatório Referente aos Terrenos das Escolas de Aprendizes Artífices", apresentado pelo arquiteto Carlos Porto, encontrado no Acervo Digital Gustavo Capanema do setor da Divisão de Obras do Ministério da Educação e Saúde, a construção do prédio da ETM iniciou em 1937 e, nesse período, a escola era denominada de Liceu Industrial de Manaus (1937-1942). O terreno foi doado por Álvaro Maia7

30 Arquivo digital está localizado no Centro de Pesquisa e Documentação de História Contemporânea do Brasil (CPDOC) - a Escola de Ciências Sociais da Fundação Getúlio Vargas.

${ }^{4}$ IFAM - Instituto Federal de Educação, Ciência e Tecnologia do Amazonas (atual nomenclatura da antiga Escola Técnica).

${ }_{5}$ Lei que estabelece as bases de organização e de regime do ensino industrial, que é o ramo de ensino, de grau secundário, destinado à preparação profissional dos trabalhadores dos transportes, das comunicações e da pesca. (BRASIL, 1942).

'Decreto que aprova o Regulamento do Quadro dos Cursos do Ensino Industrial. (BRASIL, 1942).

7 Álvaro Botelho Maia nasceu no município de Humaitá em 1893, formou-se em bacharel em Direito pela Faculdade Livre de Ciências Jurídicas e Sociais do Rio de Janeiro, foi poeta, jornalista, professor no Ginásio Amazonense e Colégio Dom Bosco. Em 1935 foi Senador Federal e com o golpe político do Estado Novo em 1937 foi nomeado Interventor Federal 
interventor federal nomeado por Getúlio Vargas e no dia 07 de dezembro de 1937 uma cerimônia realizada "lançou a pedra fundamental" para o início da construção do edifício.

Estiveram presentes ao ato, o interventor Alvaro Maia, acompanhado do seu secretário; coronel Oto Feio da Silveira, comandante da guarnição federal e do 27 B.C.; o chefe de polícia dr. Ruy Araujo; o prefeito Antonio Maia, comandante da força estadual, magistrados, jornalistas, funcionários públicos federais, estaduais e municipais e grande número de populares, além do bispo D. Basílio Pereira, acompanhado do monsenhor Raimundo de Oliveira. D. Basílio benzeu a pedra, usando nessa ocasião da palavra, o dr. Paulo Sarmento, diretor da escola (CPDOC, 1939, p.64).

O Jornal do Comercio de 7 de dezembro de 1937 ao publicar a notícia sobre essa cerimônia destacou que a obra estava "moldada de acordo com as mais rigorosas exigências da engenharia moderna, obedecendo às normas da arquitetura pedagogica" e "será, no gênero, o primeiro do Brasil, pertencendo à série A do plano referene a esses educandos". (p.1). A notícia conclui que devido ao "esforço do dr. Leopoldo Tavares da Cunha Mello8, cuja iniciativa encontrou entusiástico apoio do presidente Getúlio Vargas, do ministro Gustavo Capanema e do então governador, atual interventor, Álvaro Maia". (p.1).

Nota-se a relevância e a preocupação com o processo de construção do edifício para a sociedade em Manaus nesse período inicial da instauração do Estado Novo (1937), ocasionando a ampliação do número de matrícula: 1937 - 350 matrículas, 1938 - 470 matrículas, 1939 - 670 matrículas, (CPDOC, 1939, p.4), e assim visando o desenvolvimento econômico do país com a expansão da indústria.

A Escola Técnica de Manaus quando denominava-se Escola de Aprendizes Artífices (1910-1942), teve suas instalações em três endereços, e

permanecendo até outubro de 1945. Encerrou sua carreira política como Senador do Amazonas (BITTENCOURT, 1973, p.62-67).

8 Leopoldo Tavares da Cunha foi delegado do Partido Socialista do Amazonas, e com o fechamento do Congresso a partir da instauração do Estado Novo em 10 de novembro de 1937, foi nomeado procurador-geral junto ao Tribunal de Contas da União (MELO, L. T. da C. Biografia. In: KELLER, V. Verbete. Rio de Janeiro: CPDOC, 2010.). 
essas mudanças foram retratadas no documento "Sedes Escolares" do Arquivo Gustavo Capanema:

Quando da sua instalação, o governo do Estado cedeu-lhe um prédio que havia sido morada particular, situado num bairro distante da cidade e em logar insalubre. Apezar de não satisfazer, em absoluto, os fins vizados pela instituição, todavia aí esteve até Janeiro de 1917, quando o mesmo governo estadual poz á disposição da União, a título precário, o edifício onde estava e está hoje instalada a Penitenciária, que foi mudada para outro local. Esta nova instalação não podia, ainda, preencher as exigências do educandário, pois se tratava de um edifício que fora um presídio, com os seus corredores longos e sombrios, as suas células, as suas portas e janelas engradadas, etc. [...] foi transferida então a Escola de Aprendizes Artífices para um barracão, construído pela Municipalidade no bairro de Cachoeirinha, na falta de prédio melhor, onde pudesse se acolher (CPDOC, 1937, p.60-61)

É nesse momento histórico da Escola de Aprendizes Artífices, que a primeira instalação (1910-1916), segundo Souza (2002), estava localizada dentro das dependências da Chácara Afonso de Carvalho, na rua Urucará, no bairro Cachoeirinha, de acordo com a autora, esse prédio era "inadequado para a instalação da Escola, visto estar localizado em uma área insalubre e, [...] não era servido por nenhum tipo de transporte coletivo, como o bonde, dificultando o acesso dos alunos." (p. 48); a segunda instalação localizada na Casa de Detenção de Manaus (1917-1926), a atual Cadeia Pública Desembargador Raimundo Vidal Pessoa, na Avenida Sete de Setembro, um prédio que ficou vago quando os sentenciados foram transferidos para Paricatuba. Mello (2009), também afirma que "apesar de não ser um local adequado para o funcionamento do estabelecimento de ensino, o novo endereço trouxe alterações positivas para a escola, principalmente por apresentar fácil acesso aos alunos" (p.31); e a terceira instalação, localizada no Mercado Municipal da Cachoeirinha (1927-1936), oferecia condições inadequadas para a instalação: pavilhões de madeira, cobertos com folhas de zinco e com assoalho de chão batido (SOUZA, 2002, p.94). 
Entre os anos de 1935 a 1947, Luiz Paulo Sarmento foi o diretor da escola, acompanhou a mudança de nomenclatura da Escola de Aprendizes Artífices para Lyceu Industrial de Manaus, em seguida, Escola Técnica de Manaus, e também presenciou o processo da construção do prédio escolar.

O término da construção definitiva do edifício da Escola Técnica foi em 1941, e o prédio estava localizado entre a Av. Sete de Setembro e as ruas Duque de Caxias, Ajuricaba e Visconde Porto Alegre, ocupando uma área de $25.649,60 \mathrm{~m}^{2}$. O edifício principal tinha 2 pavimentos, com a fachada central voltada para a avenida 7 de Setembro e a ala esquerda para a rua Visconde de Porto Alegre. (CPDOC, 1937, p.64-66).

Figura 1: Novas Instalações da Escola de Aprendizes Artífices do Amazonas, em Manaus

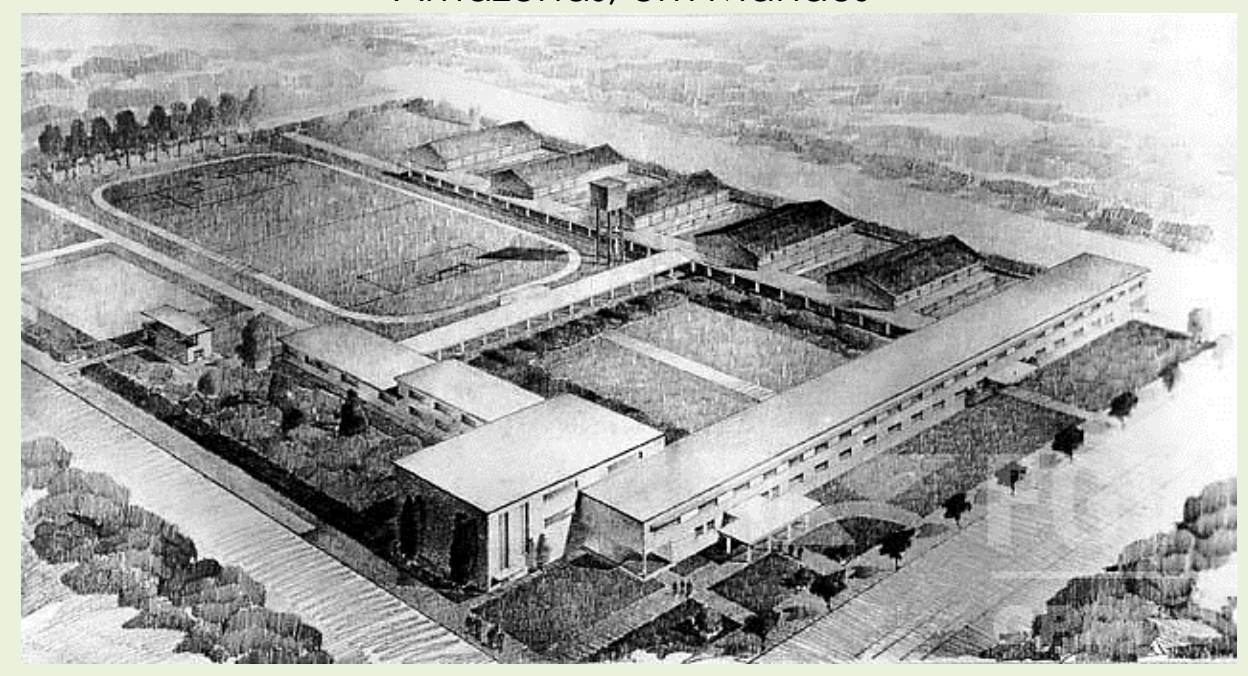

Fonte: CPDOC. Arquivo Digital. Aspectos de maquetes, instalações e atividades de instituição de ensino industrial amazonense, bem como de desfile comemorativo ao Dia do Trabalho, 1934-1945.

O edifício tinha a capacidade para receber 400 alunos, incluindo 100 internos. É relevante ressaltar que nesse mesmo período estavam sendo construídos os Liceus de São Luiz (Maranhão), de Vitória (Espírito Santo), de Pelotas (Rio Grande do Sul) e de Goiania (Goiás), e receberem o mesmo tipo de construção e instalações do edifício de Manaus. As instalações seguiam o mesmo padrão contendo: 
vestíbulo e hall dos alunos, administração (diretoria, secretaria, arquivo, portaria e inspetoria), salas de aulas, oficinas, salas de desenho, gabinete médico e dentário com salas de espera, gabinetes de física, química e história natural, museu tecnológico, salas dos professores, arrecadação, depósito de artefatos e almoxarifado, auditório (platea, balcão, palco e depósito) refeitório, (copa, cozinha e despensa), biblioteca (depósito de livros e sala de leitura), dormitório, enfermaria, quarto do vigilante, campo de desporto, corredores e galerias de circulação, instalações sanitárias, residências do diretor e do porteiro (CPDOC, 1937, p.9).

Nesse sentido, no Relatório do Ensino Pofisisonal a política do Estado Novo era constatada pelo anúncio da expansão do ensino profissional, por meio do Ministério da Educação e Saúde, que presenciava a criação das instituições, atribuindo-lhes "novos, apropriados e majestosos prédios", e equipando-os com "maquinário moderno e vultoso, criando novas secções de trabalho". (CPDOC, 1934, p.9).

Figura 2: Escola de Aprendizes Artífices do Amazonas, em Manaus

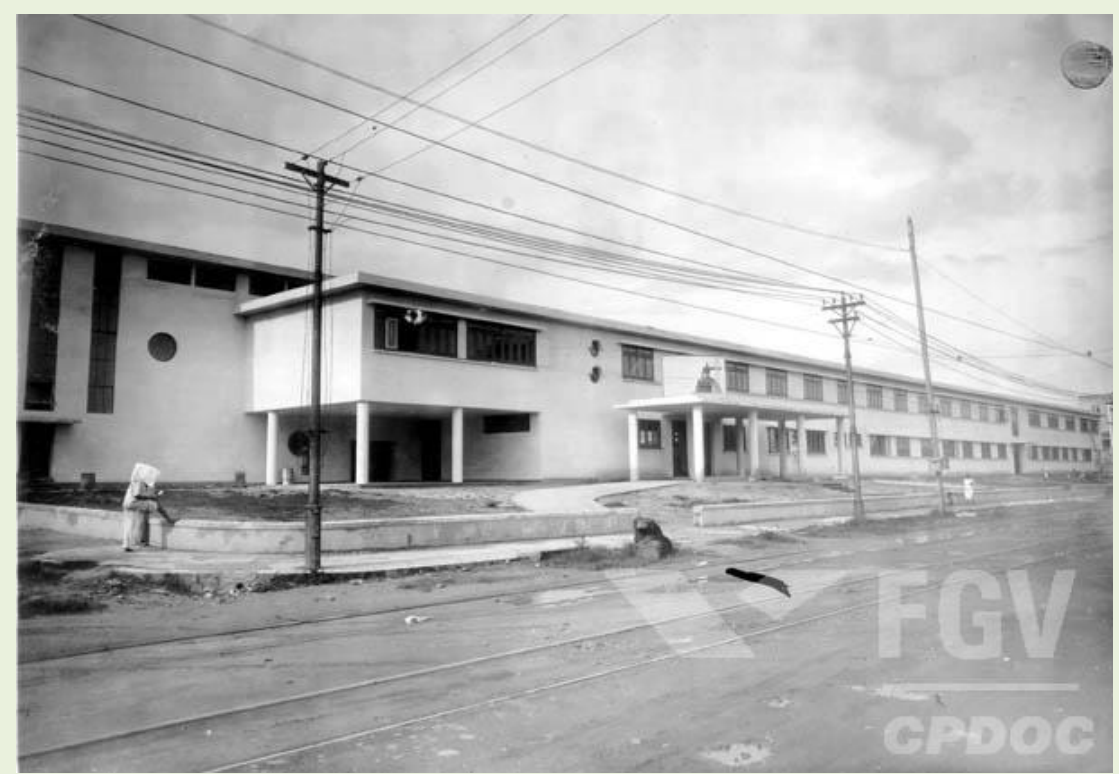

Fonte: CPDOC. Arquivo Digital. Aspectos de maquetes, instalações e atividades de instituição de ensino industrial amazonense, bem como de desfile comemorativo ao Dia do Trabalho, 1934-1945. 
Figura 3: Vista Parcial do refeitório dos alunos em 1948

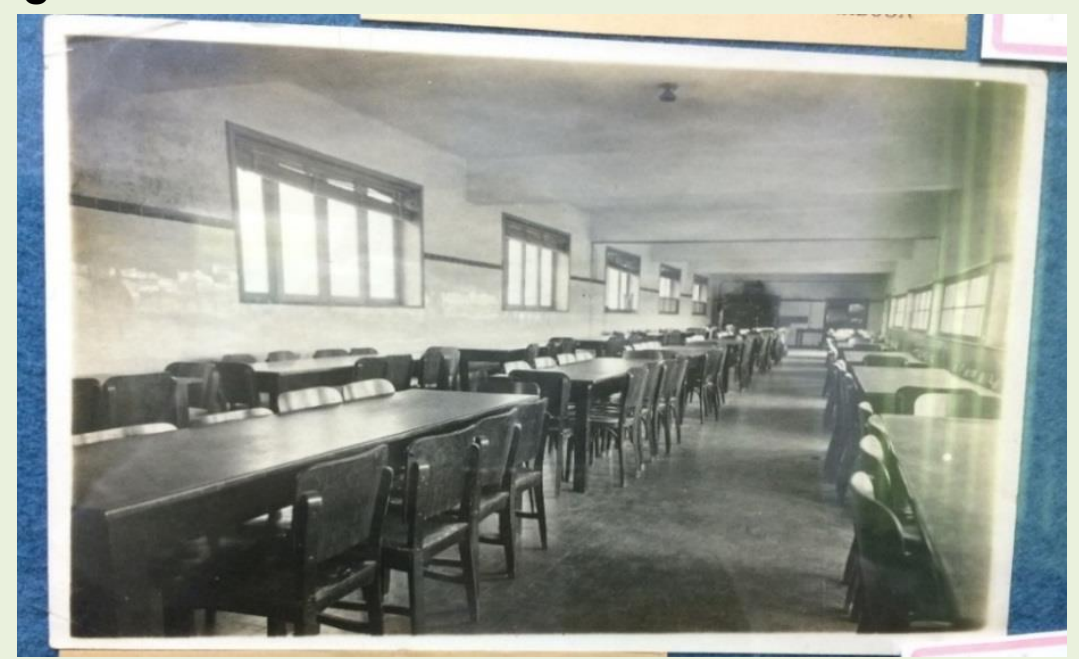

Fonte: Museu Histórico Moacir Andrade - localizado no IFAM.

As primeiras instalações da ETM estavam configuradas em: edifício principal, ala direita e ala esquerda. Nesse contexto, de acordo com o "Relatório Referente aos Terrenos das Escolas de Aprendizes Artífices" (1937, p. 66, 68):

O edifício principal contém: vestíbulo e hall dos alunos; Administração (diretoria - secretaria - arquivos - portaria inspetoria); Gabinete médico (Figura 23, p. 62) e dentário, com a respectiva sala de espera; 6 salas de aula com 2 salas de desenho com 3 gabinetes para Física - Química - História Natural; 1 museu tecnológico; Sala para docentes; Arrecadação - depósito de artefatos - almoxarifado; Instalações sanitárias; Circulação interna. A ala esquerda compreende: Auditório - platéia e balcão; Palco; Depósitos; Biblioteca (depósito de livros e sala de leitura); Refeitório (Figura 22, p. 61); Cópa - cozinha - dispensa; Dormitório - enfermaria - cabine de zelador; Instalações sanitárias; Circulação interna. A ala direita com os pavilhões das oficinas: 8 oficinas; 4 instalações sanitárias; Circulação interna; Galeria de ligação entre as alas, que serve também para o recreio dos alunos; Instalações sanitárias; Campo de desportos; Casa do diretor (Figura 21, p. 61), em 2 pavimentos, com 2 salas, 4 quartos, banheiro, água, cozinha, 2 varandas, 2 terraços, halls, quarto do creado e W.C., com casa do zelador, em 1 pavimento, com 1 sala, 3 quartos, cozinha, banheiro e varanda.

A estrutura da construção das instalações estava de acordo com as exigências e necessidades do Governo Federal vigente em 1937 , proporcionando uma localização de fácil acesso (MELLO, 2009) aos alunos, tendo a linha do bonde passando em frente da Escola, em comparação 
com a primeira instalação situada na Chácara Afonso de Carvalho (SOUZA, 2002), e configurando-se como um marco significativo para a história da instituição e do ensino profissional em Manaus.

O documento oficial "Histórico da Construção do Liceu Industrial de Manaus" (1938) consta sobre o processo da construção das instalações, no qual no dia 22 de abril de 1937, o arquiteto carioca Carlos Henrique Porto enviou para o Ministro da Educação Gustavo Capanema o anteprojeto das obras. O Ministro citou que para o Amazonas era necessário ter instalações para internato, devendo as obras estarem prontas no início de 1938. A empresa contratada Leão, Ribeiro \& Cia Ltda, era do Rio de Janeiro, e aceitou realizar as obras; assim, o Ministro Capanema enviou um manuscrito para o presidente Getúlio Vargas solicitando autorização para início das obras e obteve a aprovação como resposta.

Arruda (2010) em sua Tese, cita Barnard (1855) ao referir que este teórico "propôs dezessete princípios para a arquitetura escolar" e pode-se afirmar que esse período perpetuou e "influenciou a produção brasileira do final do século XIX e início do século XX". Constata-se que dentre esses princípios três se aproximam das instalações da Escola Técnica:

a) O local: um local, saudável, acessível de todas as partes da cidade ou bairro; longe da poeira, ruído e perigo da estrada;

b) O terreno sempre grande para prever ampliações; [...] abertos, para recreação e lazer dos alunos;

c) Preocupação com o conforto ambiental com passagem de ar fresco, arranjos da sala de aula com organização das carteiras; circulação para o professor; janelas seguras; paredes pintadas de branco (ARRUDA, 2010, p.57).

De acordo com esses aspectos, a arquitetura escolar acompanha historicamente todas as transformações econômicas, políticas, culturais e sociais de uma sociedade, refletindo e influenciando dentro do seu espaço, os indivíduos, através das modificações externas.

Mello (2009) relata que no Regimento Interno da Escola Técnica de Manaus (1942), em consonância com a Lei Orgânica do Ensino (1942), a finalidade do atendimento na Instituição destinava-se: 
- aos interesses do trabalhador, realizando a sua preparação profissional e a sua formação humana;

- aos interesses das empresas, nutrindo-as segundo as suas necessidades crescentes e mutáveis, de suficiente e adequada mão de obra;

- aos interesses da nação, promovendo continuamente a mobilidade de eficientes construtores de sua economia e cultura (MELLO, 2009, p.57).

Essa tríade: trabalhador - empresas - nação, estava interligada para propiciar mão-de-obra para o desenvolvimento da indústria no Brasil proposto pelo Estado Novo (1937-1945) através da escolarização das classes populares, enquanto a educação para a classe mais favorecida economicamente, era encaminhada para o ensino superior, e deixando explícito o dualismo na educação.

Ribeiro (1981) afirma que, com a Constituição de 1937 outorgada por Getúlio Vargas, a "orientação político-educacional capitalista" preparava os operários para as recentes exigências do mercado, e essa diferenciação entre a formação das classes favorecidas em oposição as classes menos favorecidas estava longe de ser resolvida.

Através da Lei Orgânica do Ensino Industrial (1942) os antigos Liceus Industriais deixaram de oferecer os cursos primários e passaram a "ministrar cursos de formação, de duração semelhante à do ensino secundário". (ROMANELLI, 1989, p. 168; BRASIL, 1942, p.1). Assim existia uma distinção entre a procura pela formação profissional de longa duração e a formação de rápida duração, e esta era mais almejada pelos alunos que já estavam trabalhando ou os que desejavam ingressar no mercado com mais facilidade.

Conforme o período de 1940 a 1960, em Manaus, a Escola Técnica passou por várias transformações para se adequar ao Decreto-Lei 4.127/42 Lei Orgânica do Ensino Industrial. O ensino na Lei Orgânica do Ensino Industrial (1942) estava estruturado em dois ciclos. O primeiro abrangia os cursos: Industrial Básico, Mestria, Artesanal e Aprendizagem. O segundo compreendia: Ensino Técnico e Ensino Pedagógico. Os cursos estavam classificados em: Cursos Ordinários ou de formação profissional; Cursos 
Extraordinários ou de qualificação, aperfeiçoamento ou especialização profissional; e Cursos Avulsos ou de ilustração profissional.

Os Cursos Ordinários (1 ciclo) incluíam os Cursos Industriais, Mestria, Artesanais e Aprendizagem. De acordo com a Lei Orgânica do Ensino Industrial (1942), os Cursos Industriais eram destinados ao ensino de um ofício de modo completo, necessitava de uma longa formação profissional com duração de quatro anos; os Cursos de Mestria formavam o profissional diplomado em curso industrial para o exercício da função de mestre e com duração de dois anos; os Cursos Artesanais forneciam o ensino de um oficio de duração reduzida, com duração de um ou de dois anos; e os Cursos de Aprendizagem eram destinados a ensinar metodicamente o próprio oficio dos aprendizes dos estabelecimentos industriais em período variável e horário reduzido, com duração de um, dois, três ou quatro anos.

Fonseca (1962) descreve que os Cursos de Mestria nesse período não foram muito bem aceitos pelos egressos dos cursos industriais, que preferiam se matricular nos cursos técnicos. Os alunos que apresentavam o diploma de mestre não eram vistos com "bons olhos pela indústria", devido a determinados cursos terem apenas dois anos de duração, o aluno poderia estar com dezoito anos e para a indústria essa idade "é muito pouco para quem vai desempenhar a função de mestre de oficina, quando terá de chefiar homens já encanecidos no trabalho e que não se sujeitam ao comando de um jovem, quase um menino" (FONSECA, 1962, p.268).

Os Cursos Ordinários $\left(2^{\circ}\right.$ ciclo) referem-se aos Cursos Técnicos destinados ao ensino de técnicas de caráter especifico na indústria com duração de três ou quatro anos; e os Cursos Pedagógicos estabelecia a formação do pessoal docente e administrativo do ensino industrial com duração de um ano.

As modalidades dos Cursos Extraordinários eram os Cursos de Continuação que destinava aos jovens e adultos não diplomados ou habilitados a uma qualificação profissional; os Cursos de Aperfeiçoamento e Cursos de Especialização ampliavam os conhecimentos e capacidades ou ensinava uma especialidade definida aos trabalhadores diplomados ou 
habilitados em curso de formação profissional, aos professores (das disciplinas de cultura técnica ou de cultura pedagógica) e administradores de serviços relativos ao ensino industrial. Os Cursos Avulsos estabeleciam o ensino de conhecimentos de atualidades técnicas aos interessados nessa modalidade.

No documento "Relatório - relativo ao ano de 1947" da ETM, escrito pelo Diretor Interino - Carlos Garrido Teixeira9 para o Chefe da Divisão do Ensino Industrial - Francisco Montojos, estava presente a descrição das atividades realizadas e de algumas necessidades que a escola estava passando, incluindo sobre o curso de mestria e técnico:

\begin{abstract}
Sentimos a falta de professores para os cursos de Mestria e Técnico, uma das razões ponderáveis que contribuíram para que este último curso não funcionasse, apezar do apreciável número de candidatos que nos procuram continuamente, inquirindo-nos sobre em que tempo será possível a sua concretização. Sabemos, perfeitamente, da dificuldade que existe de selecionar-se professores para os cursos técnicos e de arregimentá-los para estas paragens de setentrião. As vantagens que se lhes oferessem não podem competir com outras tantas que lhes são concorrentes, dada a procura superar a oferta nos Estados sulinos, onde a industrialização é mais evidente. Aqui em Manaus, poucos são os engenheiros que podem candidatar-se às nossas cadeiras dos cursos técnicos, visto que os existentes em número diminuto, mal podem atender aos encargos que thes são oferecidos pelo Estado (TEIXEIRA, 1947, p. 7 - 8).
\end{abstract}

Assim, nesse período verificou-se a dificuldade de contratação de professores para os cursos de mestria e técnico devido à localização da ETM ser na Região Norte, a oferta nos Estados do Sul do país ser mais atrativa financeiramente e o número reduzido de engenheiros que poderiam lecionar na escola, mas que não supria as necessidades do próprio Estado.

Em Manaus, a estrutura do ensino profissional na Escola Técnica estava configurada em Curso Industrial, Curso de Mestria e Curso Técnico. O Curso Industrial abrangia as Secções de Trabalhos de Metal e Artes Industriais; O Curso de Mestria tinha as Secções de Trabalhos de Metal e Artes Industriais; e

\footnotetext{
9 Mello (2009) relata que o Diretor Interino Carlos Garrido Teixeira era escriturário e assumiu a escola como substituto do Diretor Prof. Luiz Paulo Sarmento que se afastou por motivos de saúde.
}

Revista Exitus, Santarém/PA, Vol. 9, № 4, p. 805 - 831, Out/Dez 2019. 
- Curso Técnico, as Secções de Indústria Mecânica, Eletrotécnica, Indústria da Construção e Artes Industriais.

A Escola Técnica de Manaus oferecia no Curso Industrial e de Mestria as oficinas de: serralheria, marcenaria, artes do couro, alfaiataria, corte e costura, chapéus, flores e ornatos, e tipografia e encadernação. O Curso Técnico oferecia as oficinas de máquinas e motores, eletrotécnica, edificação, pontes e estradas e desenho técnico. Mediante esses aspectos, foi com o Decreto $n^{\circ}$ 8.673, de 3 de fevereiro de 1942 que foi aprovado o regulamento do quadro dos cursos do ensino industrial e apresentava as configurações de cada curso, secções e oficinas que foram adotadas na Escola Técnica de Manaus.

Para o ingresso nas escolas industriais, conforme a Lei Orgânica do Ensino Industrial (1942), o aluno realizava exame vestibular e testes de aptidão mental e física, como forma de eliminar o caráter "assistencialista", abandonando o critério de "miséria" e "pobreza" para acesso aos cursos profissionalizantes (MELLO, 2009, p. 58).

Nascimento (2007) dialoga sobre essa nova estrutura de ingresso nas escolas de ensino profissional, e informa as mudanças que levaram esse acontecimento:

O deslocamento do ensino profissional para o nível médio objetivava
permitir que a escola primária tivesse como função principal a
seleção dos "mais educáveis". O sentimento que transparece - pelo
menos em relação ao ensino profissional - é que as escolas de
aprendizes artífices recrutavam os alunos possivelmente "menos
educáveis", devido naturalmente a suas origens sociais e culturais.
Com essa nova graduação das etapas de escolaridade, "mesmo
que o ensino industrial recrutasse os piores dentre os concluintes do
ensino primário urbano, seu potencial de aprendizagem seria, muito
provavelmente, superior a dos "desvalidos' da situação anterior"
(NASCIMENTO, 2007, p.192).

A partir desse contexto, a Lei Orgânica do Ensino Industrial (1942) institui um novo olhar para o ensino profissional, não mais como uma norma utilizada para o ingresso somente para as classes menos favorecidas, mas, para todo o jovem que tivesse interesse e que apresentasse não ser portador de doença, estar vacinado, ter doze anos feitos e ser menor de dezessete 
anos, ter cursado o ensino primário, possuir capacidade física e aptidão mental, e ser aprovado nos exames vestibulares.

A articulação para o ensino superior foi um processo que durou quase 20 anos para que os concluintes do ensino profissional pudessem ter acesso sem restrições, independente de sua classe econômica. Nesse contexto, é necessário citar quatro leis que nortearam e efetivaram esse processo. Nascimento (2007) afirma que:

As disciplinas constantes dos currículos dos cursos profissionais, até 1959, eram distribuídas para atender basicamente a dois objetivos: contribuir para a formação profissional na atividade focada pelo curso e dificultar, ao máximo, a migração para o ensino secundário. Isso era feito, evidentemente, sob o argumento de que o objetivo do ensino profissional era formar o operário (NASCIMENTO, 2007, p. 231).

Entende-se que o aluno, ao ter cursado o primeiro ciclo do ensino profissional e desejasse o ingresso no segundo ciclo do ensino secundário (propedêutico), deveria se matricular novamente e cursar todo o período referente o almejado. Nessa mesma perspectiva, acontecia ao término de qualquer curso técnico de nível médio e o aluno desejasse ir para o ensino superior, o mesmo teria que "frequentar o segundo ciclo do curso secundário" (NASCIMENTO, 2007, p.232).

Foi com a Lei $n^{\circ} 4.024$, de 20 de dezembro de 1961 - Lei de Diretrizes e Bases da Educação Nacional, que houve alterações e flexibilidade no acesso ao ensino secundário, como foi citado no art. 34 - "o ensino médio será ministrado em dois ciclos, o ginasial e colegial, e abrangerá, entre outros, os cursos secundários, técnicos e de formação de professores para o ensino primário e pré-primário"; e superior sem a obrigação do aluno continuar na mesma formação, possibilitando o ingresso em outras áreas. Nogueira (2016) afirma que:

o fato da flexibilização do acesso a qualquer curso superior não era garantia de condições formativas iguais. Não obstante, a integração entre o ensino profissional e ensino médio na estrutura estabelecida após a Lei de Diretrizes e Bases 4.024/61 significou a aglutinação dos cursos no ciclo colegial (NOGUEIRA, 2016, p. 36). 
Percebe-se essa distinção no art. 49, parágrafo $1^{\circ}$ da Lei no 4.024, de 20 de dezembro de 1961 - LDB: as duas últimas séries do $1^{\circ}$ ciclo incluirão, além das disciplinas específicas de ensino técnico, quatro do curso ginasial secundário, sendo uma optativa; no parágrafo $2^{\circ}:$ : $2^{\circ}$ ciclo incluirá além das disciplinas específicas do ensino técnico, cinco do colegial secundário, sendo uma optativa.

\section{CRIAÇÃO DA ESCOLA TÉCNICA FEDERAL DO AMAZONAS: 1965-1971}

Em 1965, através da Lei no 4.759, de 20 de agosto de 1965, que dispõe sobre a denominação e qualificação das Universidades e Escolas Técnicas Federais, ocorre a transformação da Escola Técnica de Manaus para Escola Técnica Federal do Amazonas (ETFAM). Na Lei, o Art $1^{\circ}$ informa: "as Universidades e as Escolas Técnicas da União, vinculadas ao Ministério da Educação e Cultura, sediadas nas capitais dos Estados serão qualificadas de federais e terão a denominação do respectivo Estado." Na Escola Técnica a modificação ocorreu no mesmo ano e denominou-se Escola Técnica Federal do Amazonas (ETFAM).

Essas transformações "foram sendo regulamentadas juntamente com o ensino, conforme o projeto de governo do momento, que tinha como meta o desenvolvimento do país" (LOBATO, 2012, p.43). De acordo com Nogueira (2016), a ideologia do desenvolvimento cumpriu no campo ideológico o que foi formalizado legalmente:

[...] a política educacional brasileira, articulada nacionalmente a partir da década de 1930, sintetiza a redenção da questão política à questão econômica, uma vez que uma análise da educação como prática social e uma das mediações da relação Capital X Trabalho demonstra que os textos legais foram ajustados para atender às demandas capitalistas em território brasileiro. A partir da década de 1960 e 1970, foram orquestrados pela ideologia do desenvolvimento, na década de 1990, atenderam aos princípios neoliberais e, a partir da década de 2000, ressuscitaram a falácia do desenvolvimento para combater a onda neoliberal sem ameaçar a ordem capitalista (p. 30).

Tais demandas significaram a influência do sistema capitalista em tornar o Brasil um país industrializado e a estruturação do ensino industrial serviu a esses propósitos, marcados por uma política de educação, com 
forte apoio militar, voltada para a profissionalização em nível médio, com os cursos técnicos (SILVA; MEDEIROS NETA, 2017).

A criação da Zona Franca de Manaus pela Lei 3.173, de 6 de junho de1957 demarca para a capital do estado do Amazonas a condição comercial e idustriária para atendimento na região Amazônica, brasileira e internacional.

Art. $1^{\circ}$ - É criada em Manaus, capital do Estado do Amazonas, uma zona franca para armazenamento ou depósito, guarda, sonservação beneficiamento e retirada de mercadorias, artigos e produtos de qualquer natureza, provenientes do estrangeiro e destinados ao consumo interno da Amazônia, como dos países interessados, limítrofes do Brasil ou que sejam banhados por águas tributárias do rio Amazonas.

O entreposto comercial e tributário abria possibilidades para o capital privado na criação de indústrias, conforme indica o Art. $4^{\circ}$, da Lei 3173, de 1957:

Art. $4^{\circ}$ - Nas dependências internas da zona franca de Manaus, constituídas pelos terrenos agregados às suas instalações portuárias, será facultado aos particulares que o desejarem arrendar terrenos para o fim de constituir depósitos de mercadorias ou montar indústrias de beneficiamento de matérias primas provenientes das repúblicas limítrofes à Amazônia ou daquelas que sejam banhadas por cursos fluviais tributárias do rio Amazonas, bem como os correspondentes serviços de escritório.

A demanda industrial de Manaus estava demarcada e mesmo sendo a Zona Franca de Manaus regulamentada, posteriormente pelo Decreto-Lei 288 de 1967, em 1959 (dois anos após a criação da Zona Francda de Manaus) é criada, pelo presidente da República Juscelino Kubitschek, a Lei 3.552, de 16 de fevereiro que modifica a organização das insitutições de ensino industrial

Duas situações são interessantes nessa reforma. A primeira diz respeito à especialização que os cursos técnicos dessas escolas deveriam atender, de acordo com a economia e a experiência das organizações profissionais da região (Parágrafo Único, do art. $5^{\circ} \mathrm{c} / \mathrm{c}$ art. $6^{\circ}$ ). A segunda, na 
organização das escolas pelo conselho de representantes escolhidos pelo presidente da República.

Art. 17, $\S 1^{\circ}$ - O Conselho será composto de seis representantes da comunidade, escolhidos pelo Presidente da República, mediante proposta, em lista tríplice elaborada pelo Ministério da Educação e Cultura, depois de ouvida a Diretoria do Ensino Industrial, renovandose, cada dois anos, por um terço de seus membros.

O primeiro conselho da ETFAM em 1960 foi composto pelo professor Aderson Andrade de Menezes, pelos industriais Isaac Benayon Sabbá, Mário das Neves Guerreiro, Armando Mesquita, pelos engenheiros Antonio Carlos Rhossard Guimarães e Elias Morkazel, além do presidente, o professor José Dias Barbosa. A partir de 1962, o primeiro curso técnico criado, dentro dessa nova estrutura, foi o de eletrotécnica e em seguida os de edificações e estradas. Os alunos das turmas dos cursos de eletrotécnica e edificações tiveram suas formaturas em 1967, conforme o documento do DAE ${ }^{10}$ (1999), encontrado na biblioteca do IFAM formava a primeira turma no curso de Eletrotécnica e Edificações, cursos esses presentes ainda em:

Em 1967 a Escola Técnica Federal do Amazonas entregava ao Parque Industrial de Manaus a primeira turma de técnicos de $2^{\circ} \mathrm{grau}$, na modalidade Eletrotécnica, vindo em seguida os técnicos em Edificações, em um crescimento de novos cursos que perdura até os dias de hoje.

Esse documento confirma a realidade do capitalismo em Manaus por meio da necessidade de trabalhadores, na inserção dos jovens nas indústrias frente à política de integração nacional e desenvolvimentista para a Amazônia, por meio dos grandes projetos.

\section{TRAJETÓRIA DAS POLÍTICAS EDUCACIONAIS PARA O ENSINO PROFISISONAL}

Para compreender a ascensão do Ensino Profissional no Brasil destacase que foi na época do Estado Novo (1937-1945) que ocorreu a expansão desse ensino, e assim, sucedeu um momento histórico marcado pelo governo autoritário de Getúlio Vargas no qual assegurava "poderes irrestritos

\footnotetext{
10 DAE - Departamento de Apoio ao Ensino.
} 
ao presidente" e redefiniu a "estrutura do Estado e suas relações com a economia e a sociedade" (VIEIRA, 2008; MACHADO, 1980).

No período de 1942 a 1946, foi organizada uma série de Decretos e Leis denominadas Leis Orgânicas do Ensino e conhecidas como Reforma Capanema, elaborada pelo Ministro da Educação Gustavo Capanema, e que constituiu uma nova organização para o ensino. As respectivas Leis constituíram-se em onze documentos para a orientação do ensino industrial, secundário, comercial, primário, normal e agrícola.

Os primeiros Decretos-Leis (1941 a 1943) foram contemplados na gestão de Getúlio Vargas e do Ministro da Educação Gustavo Capanema: Decreto-lei n. 4.073, de 30 de janeiro de 1942 - Lei Orgânica do Ensino Industrial; Decreto-lei n. 4.048, de 22 de janeiro de 1942 - Cria o Serviço Nacional de Aprendizagem dos Industriários (SENAI); Decreto-lei n.4.244 de 9 de abril de 1942 - Lei Orgânica do Ensino Secundário; e Decreto-lei n.6.141, de 28 de dezembro de 1943 - Lei Orgânica do Ensino Comercial.

Sob o governo de José Linhares e do Ministro Raul Leitão da Cunha, foi promulgado em 1946 os seguintes Decretos-Leis: Decreto-lei n. 8.529, de 02 de janeiro de 1946 - Lei Orgânica do Ensino Primário; Decreto-lei 8.530, de 02 de janeiro de 1946 - Lei Orgânica do Ensino Normal; Decretos-lei n 8.621, de 10 de janeiro de 1946 - Criação do Serviço Nacional de Aprendizagem Comercial (SENAC); e Decreto-lei n. 9.613 de 20 de agosto de 1946 - Lei Orgânica do Ensino Agrícola.

Com a Lei Orgânica do Ensino Industrial (1942), a educação profissional teve um relevante destaque no Brasil e consequentemente houve a necessidade de mão-de-obra qualificada para o mercado, principalmente para o trabalho nas indústrias.

Em 1942, o Decreto da Lei Orgânica do Ensino Industrial e o Decreto do Serviço Nacional da Aprendizagem (SENAI) foram assinados simultaneamente, cujo desenvolvimento do processo foi planejado por Getúlio Vargas. Esse movimento ocorreu devido à distinção entre as escolas industriais e escolas de aprendizagem, no que se refere à formação 
profissional, e aos alunos que frequentavam as escolas de aprendizagem já estarem trabalhando (o que não ocorria nas escolas industriais).

A formação no curso de aprendizagem "era entendida como uma parte da formação pretendida pelo curso básico industrial" aos alunos dos "estabelecimentos industriais" (BRASIL, 1942), e assim, a duração do curso de aprendizagem seria de um a quatro anos. Houve uma modificação no decreto permitindo o ingresso desses alunos (que tivessem completado 2 anos no mínimo) na $2^{a}$ série do curso básico industrial (CUNHA, 2000).

Dessa forma Cunha (2000) descreve esse movimento como "um conflito entre a pretensão do Ministério da Educação de controlar todo o ensino industrial, inclusive a aprendizagem" e "a orientação da Presidência da República, partidária do seu controle pelas entidades patronais via Ministério do Trabalho" (CUNHA, 2000, p.101).

\section{a) A Lei Orgânica do Ensino Industrial}

O artigo $1^{\circ}$ do Decreto-lei n. 4.073, de 30 de janeiro de 1942 estabelece:

as bases de organização e de regime do ensino industrial, que é o ramo de ensino, de grau secundário, destinado à preparação profissional dos trabalhadores da indústria e das atividades artesanais, e ainda dos trabalhadores dos transportes, das comunicações e da pesca (BRASIL,1942, p.1).

Essa legislação organizava o ensino industrial em 2 ciclos, sendo que o primeiro refere-se ao ensino industrial básico, o ensino de maestria, o ensino artesanal e ensino de aprendizagem; e o segundo abrange o ensino técnico e o pedagógico. Cunha (2000) descreve que houve o deslocamento de todo o ensino profissional para o grau médio, os cursos de mestria e de artesanato "tiveram duração efêmera ou nunca funcionaram" e não se encontra os registros nas "estatísticas do Ministério da Educação" (p.100).

Assim os cursos de ensino industrial básico e o de aprendizagem foram desenvolvidos em instituições distintas. $O$ ensino industrial básico seria desenvolvido nas Escolas Técnicas com ofícios que tivessem longa duração em oficinas especializadas. A modalidade - Aprendizagem, seria ministrada 
em "serviços" associando escola e trabalho, e ao "ensino de parte de cada ofício industrial" (CUNHA, 2000, p. 96).

Fonseca (1962) relata que a Lei Orgânica do Ensino Industrial (1942):

Estabeleceu, ainda, uma medida de extraordinária importância quando definiu o ensino industrial como de segundo grau, em paralelo com o ensino secundário. Deixava ele, assim, de pertencer ao grau primário, situando-se no mesmo nível que o secundário (p. 266).

Nesse momento a Lei Orgânica do Ensino Industrial (1942) foi essencial para os jovens de todas as classes sociais que iniciavam os estudos no ensino profissional e almejavam continuar os estudos no ensino superior, mas somente era permitido o ingresso nos cursos de "engenharia, arquitetura, química e belas artes" (FONSECA, 1962, p. 267), que fosse referente ao curso concluído nas escolas técnicas.

\section{b) SENAI - Serviço Nacional da Aprendizagem dos Industriários}

O Serviço Nacional de Aprendizagem (SENAI) foi promulgado pelo Decreto-Lei $n^{\circ} 4.048$, de 22 de janeiro de 1942 e no seu artigo $1^{\circ}$ refere-se à organização, administração, em todo o país, de escolas de aprendizagem para industriários. Após a crise econômica de 1930, esse novo momento de expansão da indústria pretendia atender o mercado com mão-de-obra e qualificar os menores aprendizes.

De acordo com o Decreto, as escolas de aprendizagem seriam de dois tipos: as estabelecidas junto às próprias empresas e as mantidas pelo sistema oficial de ensino; as disciplinas seriam de formação geral, de formação técnica e de práticas das operações do ofício. (ROMANELLI, 1989, p.166). Houve modificações no Decreto (Decreto-Lei $n^{\circ} 4.936$, de 7 de novembro de 1942) que ampliou as escolas de aprendizes, atingindo o setor dos transportes, das comunicações e da pesca.

O documento "Informações Relativas ao Ensino Industrial" destaca que o SENAI "mantém no país 77 escolas de aprendizagem, nas quais se achavam matriculados, em 1945, 15.642 alunos, dos quais 10.636 menores e 5.006 adultos" (CPDOC, 1947). 
Cunha (2000) afirma que a função da indústria era:

Elevar o Brasil ao nível das nações civilizadas, pois ela permitia ao país os atributos próprios dos países da Europa e dos Estados Unidos. Só a indústria poderia resolver os problemas econômicos que aflingiam o Brasil, pois só ela seria capaz de propiciar o desenvolvimento das foras produtivas, estabilizar a economia e levar o progresso a todas as regiões (CUNHA, 2000, p.94).

Assim, nesse período, O SENAl iniciou um ciclo positivo no desenvolvimento do ensino profissional no Brasil e, com a participação das empresas, possibilitou que o mercado contratasse e qualificasse com rapidez os trabalhadores, com a finalidade de acompanhar a "expansão econômica da época" (ROMANELLI, 1989, p.168).

Para explicar como se configurava em Manaus, Fonseca (1962) afirma que o início do funcionamento do SENAl foi em 1947 até 1951 (sob o chamado regime de acordo) ${ }^{11}$, após esse período houve a inauguração da Escola SENAl de Manaus no dia 15 de fevereiro de 1959, sob a direção de José Florêncio da Cunha Batista (Delegado Regional do SENAI no Estado), e oferecia, inicialmente as oficinas de carpintaria e marcenaria. (p.17). Nascimento (2007) destaca sobre a criação do SENAI ao referir como uma "estratégia oficial do governo":

A tática governamental ao criar um organismo mantido e administrado pela própria indústria com o propósito de formar e especializar mão-de-obra que de fato atendesse as necessidades produtivas, o que não fora atingido pelas escolas que ministravam o então denominado ensino industrial, foi nitidamente uma estratégia oficial do governo (fora do sistema educativo geral de educação) para a formação de trabalho do país (NASCIMENTO, 2007, p.216).

Nesse levantamento observa-se que o SENAI foi criado para o ensino dos aprendizes industriais com a duração da formação menor, em relação às Escolas Técnicas, para suprir com mais rapidez "as necessidades produtivas" da economia.

\footnotetext{
11 Nesse período o SENAI não tinha prédio próprio e funcionava em escolas oficiais existentes, mediante acordo com as autoridades competentes, ou alugava, para aquele fim, prédios particulares, instalando seus cursos (FONSECA, 1962, p.500).
} 


\section{c) Lei $\mathrm{n}^{\circ}$ 4.024/61 - Lei de Diretrizes e Bases da Educação Nacional}

A nova reorganização do ensino industrial se deu em 1961 através da Lei $n^{\circ}$ 4.024, de 20 de dezembro de 1961 pelo presidente João Gourlart. $O$ Brasil estava passando por um período pós governo de Getúlio Vargas e para que a primeira LDB fosse aprovada e implementada, a mesma passou por debates entre os que defendiam o ensino regido pelas empresas e instituições privadas, e os declaravam que a educação deveria ser laica e pública.

A estrutura da respectiva Lei estabelecia as formulações curriculares para ensino pré-primário, o primário, o médio e o superior. No capítulo III - Do ensino técnico, o Art. 47 afirma que o ensino técnico de grau médio abrange os cursos industrial, agrícola e comercial. A estrutura desses cursos foi designada em dois ciclos: o ginasial com duração de quatro anos e o colegial com duração mínima de três anos. (BRASIL, 1961).

Assim, essa estrutura na base curricular foi fundamental para que 0 acesso a educação não tivesse distinção de classe econômica e a articulação do ensino profissional, ao ensino primário e secundário, evidenciava o livre acesso ao ensino superior daqueles estudantes que tinham cursado qualquer um dos cursos profissionais.

\section{CONSIDERAÇÕES FINAIS}

O ensino profissional nas décadas de 1940 a 1960 passou por várias alterações em sua estrutura para atender a demanda do mercado capitalista que beneficiava somente as classes mais favorecidas, enquanto que as camadas populares trabalhavam para sustentar essa economia. As desigualdades estavam expostas, mas as políticas voltadas para o ensino profissional tentavam atenuar essas diferenças proporcionando uma educação para todos.

Entendemos que os processos de formação do trabalhador, desde a Reforma de Gustavo Capanema e por meio da Lei Orgânica do Ensino Industrial, sofrem modificações que são incluídas nas leis de ensino, mostrando a relação do mundo do trabalho com os processos 
educacionais. E a compreensão dos pressupostos teóricos dos Decretos e Leis nos permite entender as contradições que impulsionaram as transformações no ensino profissional.

A luta do ensino profissional pelo reconhecimento na educação foi um processo árduo desde a sua criação em 1909 pelo presidente Nilo Peçanha, até a LDB - Lei 4.024/61. Devido às discriminações contra esse ensino, limitações de acesso para outras modalidades, a influência do momento histórico, a política vigente, observam-se transformações em que a Escola Técnica de Manaus (1942-1965) foi adequando o seu currículo e a sua identidade nesse período, como as marcas das reformulações capitalistas na região impregnadas pela política econômica e educacional nacional.

O estudo histórico da Escola Técnica de Manaus demonstrou não apenas as mudanças curriculares nessa instituição de ensino, mas as de definição espacial, estrutura física, administrativa, de atendimento aos alunos, frente às determinações das políticas educacionais na instituição desde o início da sua criação como Escola de Aprendizes Artífices até se tornar Escola Técnica Federal do Amazonas.

\section{REFERÊNCIAS}

ARRUDA, Â. M. V. Arquitetura dos edifícios da escola pública no Brasil (18701930): construindo espaços para a educação. Tese de Doutorado.Campo Grande, MS. Programa de Pós-Graduação em Educação. Centro deCiências Humanas e Sociais. Universidade Federal de Mato Grosso do Sul, 2010.

BITTENCOURT, A. Dicionário amazonense de biografias: vultos do passado. Rio de Janeiro, Conquista, 1973.

BRASIL. Constituição (1937). Constituição dos Estados Unidos do Brasil. Rio de Janeiro, 1937. Disponível em:

<http://www.planalto.gov.br/ccivil_03/constituicao/constituicao37.htm > Acesso em: 07 de jan. 2018.

BRASIL. Decreto-Lei $n^{\circ}$ 4.048, de 22 de janeiro de 1942. Cria o Serviço Nacional de Aprendizagem dos Industriários (SENAI). Disponível em: < http://www.planalto.gov.br/ccivil_03/decreto-lei/1937-1946/Del4048.html> Acesso em: 13 de jan. 2018. 
BRASIL. Decreto-Lei $\mathbf{n}^{\circ}$ 4.073, de 30 de janeiro de 1942. Lei Orgânica do Ensino Industrial. Disponível em: < http://www2.camara.leg.br/legin/fed/declei/19401949/decreto-lei-4073-30-janeiro-1942-414503-publicacaooriginal-1-pe.html> Acesso em: 05 de jan. 2018.

BRASIL. Decreto $n^{\circ}$ 8.673, de 3 de fevereiro de 1942. Aprova o Regulamento do Quadro dos Cursos do Ensino Industrial. Disponível em: <http://www2.camara.leg.br/legin/fed/decret/1940-1949/decreto-8673-3fevereiro-1942-459565-publicacaooriginal-1-pe.html> Acesso em: 05 de jan. 2018.

BRASIL. Lei $n^{\circ}$ 4.024, de 20 de dezembro de 1961. Fixa as Diretrizes e Bases da Educação Nacional. Disponível em: < http://www2.camara.leg.br/legin/fed/lei/1960-1969/lei-4024-20-dezembro1961-353722-publicacaooriginal-1-pl.html> Acesso em: 17 de jan. 2018.

BRASIL. Lei 3.173, de 6 de junho de 1957. Disponível em: < http://www.planalto.gov.br/ccivil_03/leis/1950-1959/L3173.html> Acesso em: 30 de jul. 2018.

BRASIL. Lei 3.552, de 16 de fevereiro de 1959. Disponível em: < http://www.planalto.gov.br/ccivil_03/leis/L3552.html> Acesso em: 30 de jul. 2018.

BRASIL. Decreto-Lei $\mathbf{n}^{\circ} \mathbf{2 8 8}$, de 28 de fevereiro de 1967. Altera as disposições da Lei número 3.173 de 6 de junho de 1957 e regula a Zona Franca de Manaus. Disponível em: < http://www.planalto.gov.br/ccivil_03/Decretolei/Del0288.html> Acesso em: 30 de jul. 2018.

CPDOC. "O Ensino Profissional e o Estado Novo - relatório de 1934". In: Ministério da Educação e Saúde - Educação e Cultura. Arquivo Gustavo Capanema. Disponível em: < http://docvirt.com/docreader.net/DocReader.aspx? bib=arq_gc_g\&pagfis=7 9\&pesq=estado\%20novo > Acesso em 18 de abr. 2018.

CPDOC. "Relatório Referente aos Terrenos das Escolas de Aprendizes Artífices, 1937". In. Ministério da Educação e Saúde - Educação e Cultura. Arquivo Gustavo Capanema 1937-1945. Disponível em:< http://docvirt.com/docreader.net/DocReader.aspx? bib=arq_gc_g\&pagfis=7 0\&pesq=escola\%20de\%20aprendizes> Acesso em 06 de jan. 2018.

CPDOC. "Sedes escolares, 1937" In. Ministério da Educação e Saúde Educação e Cultura. Arquivo Gustavo Capanema 1937-1945. Disponível em:< http://docvirt.com/docreader.net/DocReader.aspx?bib=arq_gc_g\&pagfis= 1 30\&pesq=escola\%20de\%20aprendizes > Acesso em 06 de jan. 2018.

CPDOC. "O Novo Prédio, 1937". In: Ministério da Educação e Saúde Educação e Cultura. Arquivo Gustavo Capanema. Disponível em: < http://docvirt.com/docreader.net/DocReader.aspx? bib=arq_gc_g\&pagfis= 1 33\&pesq=escola\%20de\%20aprendizes > Acesso em 18 de abr. 2018. 
CPDOC. "Matrícula em 1939". In. Ministério da Educação e Saúde -

Educação e Cultura. Arquivo Gustavo Capanema 1937-1945. Disponível em:< http://docvirt.com/docreader.net/DocReader.aspx?bib=arq_gc_g\&pagfis=5 3\&pesq=estado\%20novo > Acesso em 08 de jan. 2018.

CPDOC. "Informações relativas ao ensino industrial, 1947". In: Ministério da Educação e Saúde - Educação e Cultura. Arquivo Gustavo Capanema 19371945. Disponível em:

<http://docvirt.com/docreader.net/DocReader.aspx?bib=arq_gc_g\&pagfis= 499\&pesq=Informa\%C3\%A7\%C3\%B5es\%20Relativas\%20ao\%20Ensino\%20Industr ial > Acesso em 16 de jan. 2018.

CPDOC. "Histórico da Construção do Liceu Industrial de Manaus - 1938". In: Ministério da Educação e Saúde - Educação e Cultura. Arquivo Gustavo Capanema. Disponível em:

<http://docvirt.com/docreader.net/DocReader.aspx?bib=arq_gc_g\&pagfis= 41363\&pesq=escola\%20de\%20aprendizes> Acesso em 19 de mai. De 2018.

CUNHA, L. A. O ensino industrial-manufatureiro no Brasil. Revista Brasileira de

Educação, São Paulo, n.14, 2000. Disponível em:

<http://www.scielo.br/pdf/rbedu/n14/n14a06> Acesso em 10 de jan. 2018.

ETFAM. Assim é o DAE - Administração pública organiz. 1999.

FONSECA, C. S. História do ensino industrial no Brasil. 1962. $1^{\circ} \mathrm{v}$. Disponível em: <https://pt.scribd.com/document/327224020/FONSECA-Celso-SuckowHistoria-do-Ensino-Industrial-no-Brasil-pdf> Acesso em 26 de abr. 2018.

Jornal do Comercio, Manaus, 7 de dez. de 1937. Disponível em:

<http://memoria.bn.br/docreader/DocReader.aspx?bib=170054_01\&pagfis=4 $1163 \&$ pesq=paulo\%20sarmento> Acesso em 14 de abr. 2018.

Jornal do Comercio, Manaus, Lei n 4.759, de 20 de agosto de 1965. Dispõe sôbre a denominação e qualificação das Universidades e Escolas Técnicas Federais. Disponível em: <http://www2.camara.leg.br/legin/fed/lei/19601969/lei-4759-20-agosto-1965-368906-publicacaooriginal-1-pl.html> Acesso em: 30 de jul. 2018.

LOBATO, A. M. L. Re-contando a história da Escola Técnica Federal do Pará: a educação profissional em marcha de 1967 a 1979. 2012. 206 f. Dissertação (Mestrado). Curso de Mestrado em Educação Brasileira, Programa de Pósgraduação em Educação Brasileira, Universidade Federal do Ceará,

Fortaleza, 2012.

MACHADO, L. T. Formação do Brasil e unidade nacional. São Paulo: IBRASA, 1980.

MAGALHÃES, J. P. de. Tecendo nexos: história das instituições educativas. Bragança Paulista: Editora universitária São Francisco, 2004. 
MELLO, M. S. V. N. de. De escolas de Aprendizes Artífices a Instituto Federal de Educação, Ciência e Tecnologia do Amazonas: cem anos de história. Manaus: Editora, 2009.

NASCIMENTO, O. V. do. Cem anos de Ensino Profisisonal no Brasil. Curitiba: Ibpex, 2007.

NOGUEIRA, S. C. C. II Fase da política de expansão da rede federal de educação profissional e tecnológica no Amazonas: acesso ampliado e precarizado à educação pública. 2016. 212 f. Tese (Doutorado). Curso de Educação, Programa de Pós-Graduação em Educação, Universidade Federal do Amazonas, Manaus, 2016.

RIBEIRO, M. L. S. História da educação brasileira: a organização escolar. 6. ed. Campinas, SP: Autores Associados, 1981.

ROMANELLI, O. de O. História da Educação no Brasil 1930-73. Petrópolis, Vozes, 1989.

SILVA, N. M. da G. de S.; MEDEIROS NETA, O. M. de. A lei orgânica do ensino industrial e o processo de organização do serviço de orientação educacional na escola industrial de Natal (1942 - 1968). Anais do IX Congresso Brasileiro de História da Educação. João Pessoa, 2017.

SOUZA, A. C. R. de. A escola de aprendizes artífices do Amazonas: os caminhos de sua implantação e consolidação (1909-1942). 2002. $156 \mathrm{f}$. Dissertação (Mestrado) - Mestrado em História da Ciência, Pontifícia Universidade Católica de São Paulo, São Paulo, 2002.

TEIXEIRA, C. G. Relatório: relativo ao ano escolar de 1947. Manaus: Amazonas, 1947.

VIEIRA, S. L. Desejos de Reforma: legislação educacional no Brasil - Império e República. Brasília: Liber livro, 2008.

Recebido em: 06 de junho de 2018 Aprovado em: 20 de março de 2019 